\title{
Subcutaneous rupture of the Achilles tendon: basic science and some aspects of clinical practice
}

Departments of Orthopaedic Surgery and Pathology, University of Aberdeen Medical School, Polwarth Building, Foresterhill, Aberdeen AB25 2ZD, Scotland Stuart William Waterston Nicola Maffulli

Stanley W B Ewen

Correspondence to: Dr Maffulli.

Accepted for publication 5 August 1997

\author{
Stuart William Waterston, Nicola Maffulli, Stanley W B Ewen
}

Achilles, the legendary warrior and hero of Homer's Iliad, lends his name to the Achilles tendon, the thickest and strongest tendon in the human body. ${ }^{1}$ Achilles' mother Thetis attempted to make her son invulnerable by immersing him in the waters of the river Styx after being told by a prophet that her son was destined to die in battle. However, the heel by which his mother held him remained untouched by the water, and thus Achilles had a vulnerable point. Achilles did go to battle, as the leader of the forces of Myrmidons whose task was to destroy Troy. ${ }^{2}$ He killed Hector, leader of the Trojans, and Troy was subsequently captured. However, Hector's death was avenged by his brother Paris, who killed Achilles by firing a poisoned arrow into his heel.

Hippocrates is credited with the first description of injury to the Achilles tendon. He stated that "this tendon, if bruised or cut, causes the most acute fevers, induces choking, deranges the mind and at length brings death". ${ }^{3}$ Ambroise Paré, the French military surgeon regarded as the father of modern surgery, is credited with the first description of rupture of the Achilles tendon in 1575. Paré believed that the affected leg should be strapped with bandages dipped in wine and spices, but he was not hopeful of a good result. ${ }^{4}$ The first description of surgical repair of a ruptured Achilles tendon was by Polaillon in $1888 .{ }^{4}$ Tendon suture was not a new idea, as it had been advocated as early as the 10th century $\mathrm{AD}$ by an Arabian physician. In the 12th century $\mathrm{AD}$, William of Falicet, an Italian surgeon, stated that nature was unable to unite divided tendons, and that surgeons could make a much better job of it. Many researchers have attempted to elucidate the aetiology of Achilles tendon rupture, but its true nature still remains unclear. There is also still disagreement regarding the best method of treatment for an acute Achilles tendon rupture. Some workers advocate surgical repair, whereas others insist that surgery is unnecessary, and is an unacceptable risk.

\section{Method}

A computerised literature search of the entire MEDLINE database, covering the years 1966 to the present, was conducted for this review. Table 1 lists the keywords used in the search. All articles that were relevant to the subject were retrieved, either locally, or by inter-library loan. The search was not limited to the English literature, and articles in all journals were considered. The authors own personal collection of papers, and any relevant personal correspondence were also included. The references that were selected were reviewed by all authors, and judged on their contribution to the body of knowledge of this topic. The conduct and validity of any clinical studies was carefully considered, and the outcomes of management protocols were carefully scrutinised. Case reports were excluded, unless they mentioned a specific association with the condition that was thought to be relevant to the discussion. Only papers that made a significant contribution to the understanding of this condition were included in the review. This left a total of 121 publications, 87 of which were directly related to the Achilles tendon, and the remainder to tendon or tendon structure in general.

\section{The Achilles tendon}

The Achilles tendon is formed by the merging of the tendinous portions of the gastrocnemius and soleus muscles, which constitute the triceps surae muscle group in the leg. The plantaris muscle, present in $93 \%$ of persons, although related to the medial border of the Achilles tendon, does not participate in the formation of the Achilles tendon. The medial and lateral heads of the gastrocnemius muscle arise posteriorly from the femoral condyles. The soleus muscle originates from the posterior aspect of the tibia and fibula. ${ }^{6}$ The gastrocnemius tendon originates as a broad aponeurosis at the lower margin of the muscle bellies. ${ }^{7}$ The soleus tendon begins as a band high on the posterior surface of soleus. Both components of the tendon vary in length and extent of fusion. The gastrocnemius component varies from 11 to $26 \mathrm{~cm},{ }^{7}$ the soleus component varies from 3 to $11 \mathrm{~cm}$. From its origin, the Achilles tendon becomes progressively rounded, to a level of about $4 \mathrm{~cm}$ above the calcaneus. ${ }^{8}$ The tendon inserts onto the calcaneus posterior to the superior calcaneal tuberosity. ${ }^{9}$ The fibres of the Achilles tendon spiral through $90^{\circ}$ during its descent. Therefore fibres that lie medially proximally become posterior distally. This arrangement permits elongation and elastic recoil within the tendon, and allows stored energy to be released during the appropriate phase of locomotion. ${ }^{8}$ This stored energy allows the generation of higher shortening velocities and greater instantaneous muscle power than could be achieved by muscle fibres alone. ${ }^{10}$ The region of the calcaneal insertion of the Achilles tendon is highly specialised. ${ }^{11} \mathrm{~A}$ subcutaneous bursa (located between tendon and skin) is variably present. A retrocalcaneal bursa lies between tendon and the calcaneum. ${ }^{9}$ These bursae reduce friction between tendon and the surrounding tissues. 
Table 1 Keywords used to search the MEDLINE database

\begin{tabular}{lll}
$\begin{array}{l}\text { Keywords for main } \\
\text { Achilles tendon }\end{array}$ & \\
Athletic injuries & Extracellular matrix & Tendinitis \\
Biomechanics & Incidence & Tendon \\
Collagen & Postoperative complications & Tendon injuries \\
Subheadings used for MEDLINE & literature search & \\
Abnormalities & Growth and development & Physiopathology \\
Anatomy and histology & Injuries & Surgery \\
Blood supply & Innervation & Transplantation \\
Chemistry & Metabolism & Ultrasonography \\
Cytology & Pathology & Ultrastructure \\
Drug effects & Physiology & \\
\hline
\end{tabular}

\section{Tendon structure}

Tendons act as transducers of force from muscle to bone. The basic constituent is collagen, which accounts for $70 \%$ of the dry weight of a tendon. ${ }^{1}$ Approximately $95 \%$ of tendon is collagen type $\mathrm{I},{ }^{12}$ with elastin present in only very small amounts. ${ }^{12}$ This is of functional significance, as elastin can undergo up to $200 \%$ strain before failure. If the elastin content of tendon were high, there would be a decrease in the magnitude of force transmitted to bone. Collagen fibrils are bundled into fascicles that contain blood vessels, lymphatics, and nerves. ${ }^{13}$ Fascicles are grouped together, surrounded by epitenon, to form the gross structure of the tendon. The entire structure is further enclosed by paratenon. A thin layer of fluid present between the paratenon and the epitenon, permits tendon movement with reduced friction.

Collagen typing experiments by Coombs et $a l,{ }^{14}$ using material from normal and ruptured Achilles tendons demonstrated that the normal Achilles tendon consists almost entirely of type I collagen, whereas ruptured Achilles tendons also contained a significant proportion of type III collagen. Fibroblasts cultured from ruptured Achilles tendons were found to produce both type I and type III collagen. The presence of type III collagen may account for the decreased resistance of tendon to tensile forces, and may therefore predispose to spontaneous rupture.

TENDON CELLS

The cellular component of tendon tissue is the fibroblast. These are observed as stellate cells in cross sections of tendon, and appear to occupy rows when seen in longitudinal section (fig 1). ${ }^{15}$ The orderly arrangement of fibroblasts in tendon is probably a consequence of the uniform centrifugal secretion of collagen around the column of cells. ${ }^{16}$ Fibroblasts produce both the fibrillar and the non-fibrillar components of the extracellular matrix. ${ }^{17}$ Fibroblasts can also reabsorb collagen fibres, ${ }^{18}$ although this has been disputed by some authors. ${ }^{19}$ The normal Achilles tendon shows a well organised arrangement, contrasting with the appearance of ruptured one (fig 2).

\section{The blood supply of tendons}

Mayer $^{20}$ described how tendons may receive their blood supply from three sources: the musculotendinous junction, vessels in surrounding connective tissue, and the tendoosseus junction. Håstad et $a l^{21}$ injected radio-

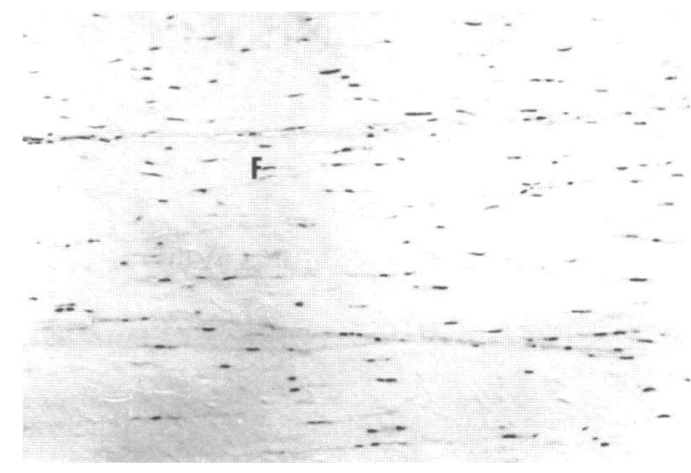

Figure 1 Low magnification appearance of normal Achilles tendon. Fibroblast nuclei $(F)$ can be clearly seen. Note the longitudinal arrangement of fibroblasts into columns.

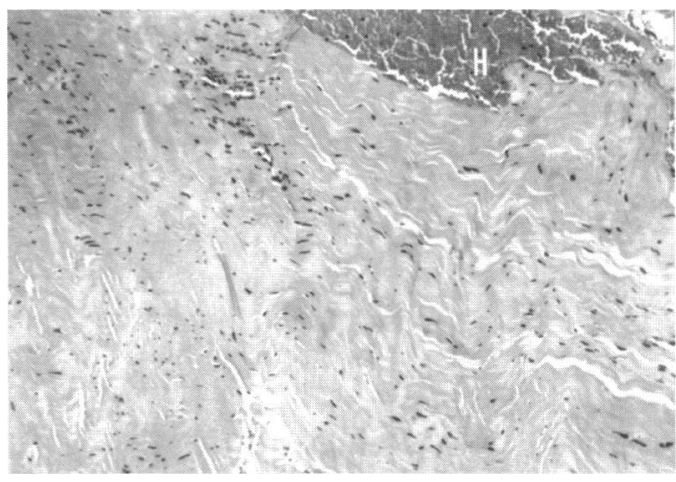

Figure 2 Low magnification appearance of ruptured Achilles tendon. Note the disorganised appearance of the tissue. Haemorrhage $(H)$ into the tendon substance is also present.

active sodium $\left({ }^{24} \mathrm{Na}\right)$ into the Achilles tendons of volunteers, and measured its clearance time. The "clearance constant" for ${ }^{24} \mathrm{Na}$ was significantly higher in younger subjects, indicating that tendon blood flow was higher in younger people, and decreased with age. Lagergren and Lindholm ${ }^{22}$ demonstrated that the Achilles tendon had a very small number of vessels, especially in the mid-portion of the tendon. More than three decades later, SchimdtRolfing $e t a l^{18}$ used epoxy resin injection into the vascular system of the leg to show that blood vessels ran from the paratenon into the substance of the Achilles tendon. They also showed that no vessels ran directly from the bone into the tendon, and that blood vessel density in the middle part of the Achilles tendon was small compared with the proximal part. This contrasts with the findings of Åstrom and Westlin in $1994 .^{23}$ Using laser Doppler flowmetry, they showed that blood flow was evenly distributed throughout the Achilles tendon. They did however acknowledge that tendon blood flow may vary according to age, sex, and loading conditions.

\section{Tendon biomechanics}

Fukashiro et $a l^{4}$ have measured a peak force of $2233 \mathrm{~N}$ within the human Achilles tendon by direct in vivo measurement. Komi et $a l^{25}$ have described the pattern of force generation within the human Achilles tendon using buckle-type force transducers attached to the ankles of human volunteers. During walking, force builds up within the tendon before the 


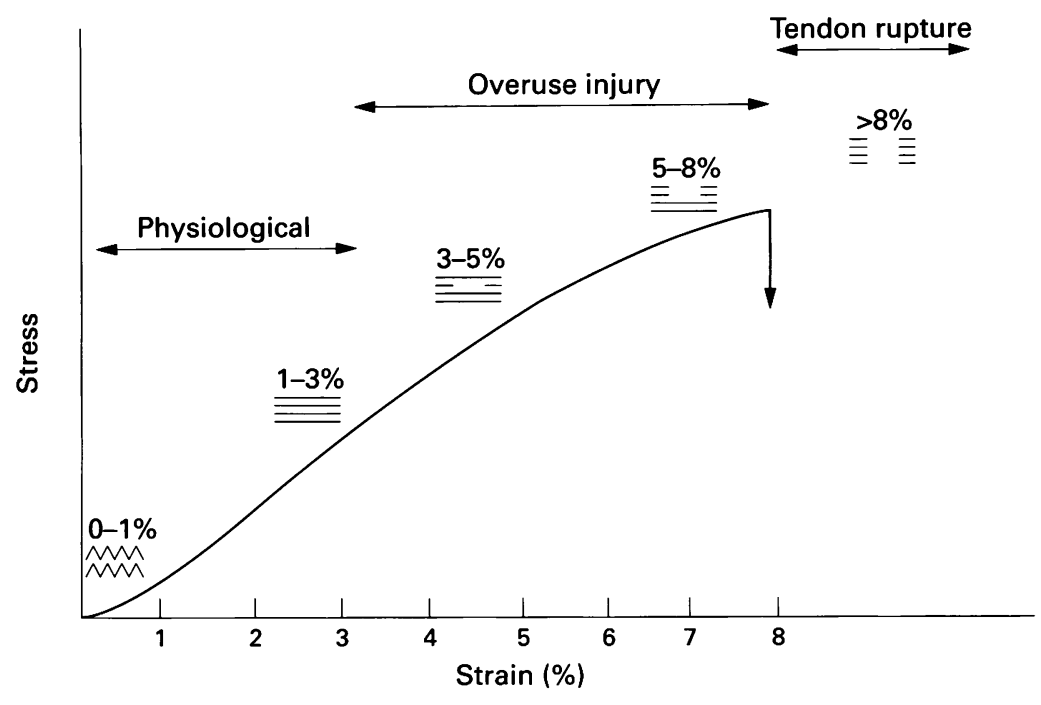

Figure 3 Stress-strain curve for tendon. Adapted from Leadbetter W B. "Cell-matrix response in tendon injury". Clin Sports Med 1992;2:573-8.

heel strikes the ground. The force is then suddenly released for $10-20 \mathrm{~ms}$ during early impact. Thereafter, force builds up relatively fast until it reaches a peak at the end of the push-off phase. A similar pattern is observed during running. Ippolito et $a l^{26}$ have observed actin and myosin in tenoblasts. They suggested that the tendon itself may have an active mechanism of contraction-relaxation, which could regulate the transmission of force from muscle to bone.

A stress/strain curve can be produced for the Achilles tendon. The curve has four regions (fig 3). In its resting state, a tendon has a wavy configuration, which is a result of crimping of the collagen fibrils. ${ }^{1}$ When tensile force is applied, the tendon loses this wavy configuration. This accounts for the toe region of the stress/strain curve. Collagen fibres deform and respond linearly to increasing tendon load. Most loads that the Achilles tendon is subjected to cause a strain less than $4 \% .{ }^{13}$ If the strain placed on tendon remains at less than $4 \%$, the tendon will regain its original configuration when the load is removed. At strain levels between $4 \%$ and $8 \%$, the collagen fibres will start to slide past one another as cross links fail. At strain levels greater than $8 \%$, macroscopic rupture of the tendon will occur because of the tensile failure of the fibres and shear failure between fibres.

\section{Epidemiology of Achilles tendon rupture} Rupture of the Achilles tendon is comparatively common. Its incidence in the general population is difficult to determine, but appears to have been increasing over the past decade. ${ }^{27}$ Recently, Leppilahti et $a l^{27}$ estimated the incidence of Achilles tendon rupture in 1994 to be around 18 per 100000 in the city of Oulu, Finland. Most Achilles tendon ruptures occur during sport. A review of literature discussing the epidemiology of Achilles tendon rupture yielded a range of figures for patients participation in sport, ranging from $44.4 \%$ to $83 \%$. $^{28}$ Badminton players seem to be particularly vulnerable to Achilles tendon rupture, as $52.3 \%$ of patients injured while playing
Table 2 Conditions associated with Achilles tendon rupture

\begin{tabular}{ll}
\hline Associated conditions & \\
\hline $\begin{array}{l}\text { Hereditary } \\
\text { Infective }\end{array}$ & $\begin{array}{l}\text { Osteogenesis imperfecta } \\
\text { Syphillis, gonorrhoea, tuberculosis }\end{array}$ \\
$\begin{array}{l}\text { Inflammatory } \\
\text { Iatrogenic }\end{array}$ & $\begin{array}{l}\text { Rheumatoid arthritis, SLE, gout } \\
\text { Corticosteroid use, fluroquinolone } \\
\text { antibiotics }^{4041}\end{array}$ \\
Others & Back pain, sciatica
\end{tabular}

SLE = systemic lupus erythematosus

* Irwin AS, Maffulli N, Porter RWP, Smith F. Tendo Achilles rupture and prolapsed intervertebral disc. A possible association? Read at the 13th meeting of the North East of Scotland Orthopaedic Association, Aberdeen, 14 May 1994.

sports were playing badminton at the time of injury. ${ }^{29}$ Achilles tendon rupture is more common in men, with a male:female ratio varying from $2: 1$ to $12: 1 .^{3}{ }^{30}$ This probably reflects a greater prevalence of sports participation in men, although there may be other as yet unrecognised factors. The left Achilles tendon is more frequently ruptured than the right, ${ }^{6}$ probably because of a higher prevalence of right sided dominance resulting in people pushing off with their left legs. ${ }^{6}$ The typical patient presenting to hospital with an acutely ruptured Achilles tendon is a middle aged man working in a white collar profession who plays sport occasionally. ${ }^{31}$ Patients presenting with an Achilles tendon rupture are most commonly in the third or fourth decade of life ${ }^{32}$ with a mean age of 40.4 years, ranging between 16 and $87 .^{32}$

Jozsa et $a l^{334}$ noted an association between the incidence of Achilles tendon rupture and blood group $\mathrm{O}$. The incidence of blood group O within the study group was significantly higher than in the general Hungarian population. Kujala $e t a l^{35}$ also noted a relation between ABO blood groups and Achilles tendon rupture. The $\mathrm{ABO}$ blood group gene is located on chromosome 9, a chromosome where no known collagen genes are located.

\section{Aetiology}

Spontaneous rupture of the Achilles tendon has been associated with a multitude of conditions, which are listed in table 2 . There has been little agreement in the literature regarding the aetiology of Achilles tendon rupture. There are a number of possible aetiologies, listed in table 3, and discussed below in more detail.

DEGENERATIVE THEORY

According to McMaster, ${ }^{42}$ a normal Achilles tendon does not rupture even when subjected to severe mechanical strain. He proposed that disease processes in tendons predisposed them to spontaneous rupture from apparently minor trauma. Håstad et $a l^{1}$ demonstrated that tendon blood flow decreased with increasing age, and other authors have stated that the segment of the Achilles tendon that is clinically

Table 3 Possible aetiologies of Achilles tendon rupture

Degeneration $^{182122} 36$ 42-44

Corticosteroids (intra-/peritendinous, oral) ${ }^{40} 47-52$

Fluoroquinolone antibiotics ${ }^{41534}$

Hyperthermia ${ }^{55-57}$ 
prone to rupture is relatively avascular compared with the rest of the tendon. ${ }^{1822} \mathrm{Kuwada}^{43}$ proposed that "footstrike haemolysis" may also contribute to the supposed vascular impairment within the Achilles tendon. The impact of the foot striking the ground could destroy normal red blood cells, and, in extreme cases, this could give rise to an anaemic state. If this occurred in people with chronic Achilles tendinitis, it might predispose to tendon degeneration and subsequent rupture. However, there is no scientific support for such a hypothesis.

Arner $e t a l^{36}$ reported a series of 74 cases of Achilles tendon rupture. Histologically, all tendons exhibited degenerative changes. However, a significant number $(62.1 \%)$ of their specimens were obtained more than two days after rupture, thus making it difficult to say whether degeneration had taken place before rupture or between the rupture and the time of repair Davidisson and $\mathrm{Salo}^{44}$ reported two cases of Achilles tendon rupture that were repaired on the day of rupture. Both these specimens demonstrated degenerative changes. The authors concluded that these degenerative changes must be regarded as primary changes, which had developed before the rupture. They suggested that the increased vascularisation seen in muscle in response to exercise also occurred in tendon, and that vascularisation of the tissue decreased with inactivity. Therefore, athletes who started training again after a period of rest were more likely to rupture their Achilles tendon at this stage. Kvist-Kristiansen et $a l^{45}$ also believed that exercise and subsequent periods of inactivity were the mechanism responsible for degenerative changes seen in tendons. Fox et $a l^{46}$ stated that athletic participation in addition to daily activity placed additional stress on the Achilles tendon, potentially leading to areas of microtrauma within the tendon. The accumulation of such episodes of microtrauma could lead to secondary degenerative changes within the tendon.

CORTICOSTEROIDS AND TENDON RUPTURE

Corticosteroid administration has been widely implicated in the aetiology of tendon rupture. Corticosteroids are administered for a variety of diseases. Balasubramaniam and Prathap ${ }^{47}$ demonstrated that infiltration of hydrocortisone into rabbit calcaneal tendons caused necrosis at the site of injection as soon as 45 minutes after injection. Corticosteroid injected tendons showed a delayed healing response compared with control tendons into which saline was injected. Corticosteroids may be implicated in the aetiology of Achilles tendon rupture to the extent that their antiinflammatory properties mask symptoms of tendon damage, ${ }^{48}$ therefore permitting people to increase their activity even with a damaged tendon. The ability of corticosteroids to interfere with healing was also believed to be important. Unverfirth and Olix ${ }^{49}$ reported on five athletes who had been given corticosteroid injections in the region of their Achilles tendons for symptoms of tenosynovitis. All suffered ruptures of their Achilles tendons. Interestingly, residua of steroid were found at the site of rupture in four of five cases. Kennedy and Willis ${ }^{50}$ demonstrated that physiological doses of corticosteroid, injected directly into the tendon, resulted in significant weakening of the tendon for up to 14 days after injection. The disruption was directly related to collagen necrosis, and restoration of tendon strength was attributable to the formation of an amorphous, acellular mass, which was thought to be a precursor of collagen. Vigorous activity should be avoided for at least two weeks after injection of corticosteroid close to a tendon..$^{50}$ Oral corticosteroids have also been implicated in the aetiology of tendon rupture. Newham et $a l^{40}$ reported a series of 12 patients in 10 years who had Achilles tendon ruptures, and who were taking long term oral corticosteroids for chronic obstructive airways disease. Four of these ruptures were bilateral.

Therefore, there is a significant amount of evidence suggesting that corticosteroid administration can be a causative factor in tendon rupture. However, not all studies on experiments on corticosteroids and tendon rupture have reported deleterious effects of corticosteroid treatment. McWhorter et at ${ }^{1}$ stated that injection of hydrocortisone acetate into the traumatised rat calcaneal tendon had no significant adverse effect, either biomechanically or histologically. In a review of corticosteroid induced tendon abnormality, Mahler and Fritschy ${ }^{52}$ stated that despite all the existing evidence regarding corticosteroids and tendon rupture, it was still impossible to say exactly what the aetiological role of corticosteroids was. They pointed out that some studies reported patients who had other risk factors for tendon rupture. He also questioned why, if corticosteroids had such a harmful effect on tendons, was the incidence of tendon rupture not much higher, because of the prevalence of corticosteroid consumption within the population.

FLUOROQUINOLONES AND TENDON RUPTURE Fluoroquinolone (4-quinolone) antibiotics such as ciprofloxacin have recently been implicated in the aetiology of tendon rupture. Royer et $a l^{41}$ have reported from France a series of 100 patients taking fluoroquinolones between 1985 and 1992 who have suffered tendon disorders, including 31 ruptures. Many of these patients had also received corticosteroid treatment, therefore making it difficult to solely implicate the fluoroquinolones. The Food and Drug Administration (FDA) have reported animal studies using fluoroquinolone doses close to those given to humans, and showed disruption of the extracellular matrix of cartilage, and depletion of collagen. The FDA subsequently recommended updating the labelling on all fluoroquinolone packing to include a warning about the possibility of tendon rupture..$^{53}$ The infections section of the British National Formulary $^{54}$ also contains a warning about fluoroquinolones. It states that "at the first sign of pain or inflammation, patients taking 4-quinolones should discontinue the treatment and rest the affected limb until the tendon symptoms have resolved". It is possible that 
Table 4 Mechanical factors in the aetiology of Achilles tendon rupture

Anatomical factors Sports equipment Training errors

Overpronation of foot on heelstrike, ${ }^{39}$ poor gastrosoleus flexibility ${ }^{39}$ Flared heels, heel tabs ${ }^{61}$

Muscle fatigue results in tendon elongation and tearing, ${ }^{39}$ torsional ischaemia resulting from unequal tensile forces ${ }^{39}$

collagen degradation seen in animals also occurs in humans, and is responsible for the tendon ruptures in patients taking such drugs.

\section{HYPERTHERMIA AND TENDON RUPTURE}

Hyperthermia may damage tendons, and some $5-10 \%$ of the elastic energy that is stored in tendons may be released as heat. ${ }^{55} \mathrm{Wilson}$ and Goodship $^{56}$ conducted in vivo experiments on equine superficial digital flexor tendons to evaluate the temperatures generated within the tendon. A peak temperature of $45^{\circ} \mathrm{C}$ was measured within the core of the tendon after just seven minutes of exercise. Previous experiments by Arancia et $a P^{7}$ have shown that fibroblasts can be damaged at temperatures above $42^{\circ} \mathrm{C}$. Exercise induced hyperthermia may be a contributory factor in tendon degeneration. A good blood supply to a tissue should help to cool overheating. Therefore, tissues such as the Achilles tendon that may have comparatively avascular areas may be more susceptible to the effects of hyperthermia.

THE "MECHANICAL" THEORY

McMaster ${ }^{42}$ proposed that a healthy tendon would not rupture, even when subjected to the most severe strain. However, Barfred, ${ }^{58-60}$ through several studies on experimental rupture of the Achilles tendon, demonstrated that, if straight traction was applied to a tendon, as in McMaster's experiments, then the risk of rupture was distributed equally to all parts of the muscle-tendon-bone complex. If oblique traction was applied, the risk of rupture was concentrated on the tendon. He calculated that, if a human Achilles tendon $1.5 \mathrm{~cm}$ wide was subjected to traction with $30^{\circ}$ of supination on the calcaneus, the fibres on the convex aspect of the tendon would be elongated by $10 \%$ before the fibres on the concave side were strained. He concluded that the greatest possibility of tendon rupture was present when the tendon was obliquely loaded, when the muscle was in maximum contraction, and when the initial tendon length was short. Such factors are probably all present in movements that occur in sports that require rapid push-off movements, such as squash and badminton. Barfred's theory is largely supported by Guillet et al (cited by Postacchini and Puddu) ${ }^{28}$ who proposed a purely traumatic theory to account for tendon rupture in young healthy patients. They believed that a healthy tendon may rupture after a violent muscular strain in the presence of various functional and anatomical factors, including incomplete synergism of agonist muscles, a discrepancy in the thickness quotient between muscle and tendon, and inefficient action of the plantaris muscle acting as a tensor of the Achilles tendon.

Sports participation plays an important part in the development of Achilles tendon problems, and training errors or poor equipment are important factors (table 4). The flared heel that is present on most sports shoes forces the rear foot into pronation when the heel strikes the ground, ${ }^{61}$ and "heel tabs" present on some shoes probably also play a part. Clement $e t a^{39}$ in a study on the aetiology of Achilles tendinitis, noted that $56 \%$ of the athletes in their study group displayed a "functional overpronation" of the foot on heelstrike. Functional overpronation produced a whipping action of the Achilles tendon, and exaggeration of this whipping action may lead to the development of microtears within the tendon. Poor flexibility of the gastrocnemius-soleus unit was also considered to contribute to overpronation. Training errors were noted in $75 \%$ of the study group, and it was suggested that, in fatigued muscles, the effect of the eccentric action of gastrocnemius and soleus, together with the gravitational elongation of the tendon occurring on footstrike, subjected the tendon to extreme stress, which could lead to the development of microtears. Unequal tensile forces on different parts of the tendon may produce a "torsional ischaemic effect"-that is, causing blanching of vessels within the tendon-and perhaps therefore contribute to the vascular impairment already existing within the Achilles tendon. ${ }^{39}$ Inglis and Sculco ${ }^{62}$ proposed that malfunction or suppression of the proprioceptive component of skeletal muscle predisposed an athlete to Achilles tendon rupture. They believed that athletes who resumed training after a period of rest were particularly susceptible to Achilles tendon rupture as a result of this malfunction. Knörzer $e t a l^{33}$ conducted experiments using $x$ ray diffraction spectra to study the behaviour of the structure of collagen during loading of tendon. Tendons that rupture without previous degenerative changes are initially damaged at the sub-microscopic fibrillar level, because of a process of intrafibrillar sliding, which occurs a few seconds before macroscopic slippage of collagen fibres. Therefore, rupture of tendons unaffected by degenerative changes may be the result of the accumulation of fibrillar damage. Such findings support the theory that a complete rupture is the consequence of multiple microruptures, and that tendon damage must reach a critical point, after which failure occurs.

\section{Mechanism of rupture}

Arner and Lindholm ${ }^{64}$ classified the history of trauma in their patients into three main categories. These mechanisms were firstly, pushing off with the weightbearing forefoot while extending the knee joint. This type of movement is seen in sprint starts, and in jumping in sports such as basketball. It accounted for $53.3 \%$ of the ruptures in their series. Secondly, sudden, unexpected dorsiflexion of the ankle, such as slipping into a hole, or falling on stairs. This mechanism accounted for $17.4 \%$ of their cases. Lastly, violent dorsiflexion of a plantarflexed foot, such as may occur after falling from a height. This mechanism accounted for $9.8 \%$ of their cases. In the rest of their cases it was difficult to quantify the exact mechanism of the injury. 


\section{Pathology}

In 1976 Puddu et $a l^{\beta 0}$ proposed a system to replace the American Medical Association definitions for tendon pathology. The major headings were (1) pure peritendinitis, (2) peritendinitis with tendinosis, (3) pure tendinosis. Tendinosis describes the degenerative processes occurring within tendon. Tendinosis is an umbrella term that includes a number of pathological processes such as hyaline degeneration with a decrease in the normal cell population, mucoid degeneration with chondroid metaplasia of tenocytes, fatty degeneration of tenocytes, lipomatous infiltration of large areas of tendon, an increase in matrix mucopolysaccharides, and fibrillation of collagen fibres. Rupture of a tendon can be secondary to this process, and is the critical end point of the degenerative process. Tendinosis is symptomless, and is disclosed only by rupture of a tendon. Patients who experience symptoms before rupture of a tendon commonly have a combination of peritendinitis and tendinosis. Kannus and Jozsa ${ }^{65}$ noted that only one third of the patients in their study of 891 ruptures had symptoms before the rupture. Arner et $a l^{\beta 6}$ observed degenerative changes in $100 \%$ of the ruptured Achilles tendons that they examined histologically. Features of the degeneration that they noted included oedematous disintegration of tendon tissue, patches of mucoid degeneration, and a severe inflammatory reaction. They also noted that around one quarter of the larger calibre arteries that were observed in the peritendinous tissue exhibited pathological hypertrophy of the tunica media and narrowing of the vessel lumen. Kannus and Jozsa $^{65}$ studied 1336 tendons to try to determine the histopathological changes that preceded a rupture. Of the 891 ruptured tendons from all sites studied, all had pathological changes, $97 \%$ of which could be described as degenerative changes. The most common degenerative lesion observed was hypoxic degenerative tendinopathy, characterised by changes in the size and shape of mitochondria, abnormal tenocyte nuclei, and occasional intracytoplasmic or mitochondrial calcification. If degeneration is advanced, then hypoxic or lipid vacuoles and necrosis may be observed. Aberrant collagen fibres can also be seen, with abnormal variations in fibre diameter, angulation, splitting and disintegration. Kannus and Jozsa also noted vascular changes in vessels of the tendon and paratenon in $62 \%$ of the 891 ruptures, which were mostly luminal narrowing caused by hypertrophy of the arterial intima and media. The available evidence suggests that changes in blood flow and subsequent hypoxia and impaired metabolism were key factors in the development of the degenerative changes that were observed in ruptured tendons. ${ }^{65}$ Degenerative changes were apparent in all tendons that had a spontaneous rupture. The interval between time of rupture and time of repair was short, thus suggesting that the degenerative changes were pre-existing. Failure of the cellular matrix has also been suggested to lead to degenerative changes within the tendon. ${ }^{66}$ Jozsa et $a l^{67}$ observed fibronectin on

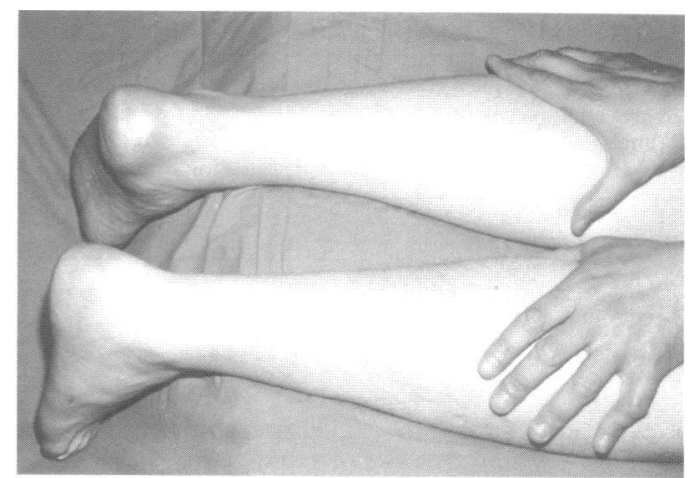

Figure 4 Simmond's calf squeeze test. The examiner gently squeezes the patient's calf muscles with the palm of the hand. If the Achilles tendon is intact, the ankle plantar flexes (left leg). If the Achilles tendon is torn, the ankle remains still, or plantarflexes minimally (right leg)

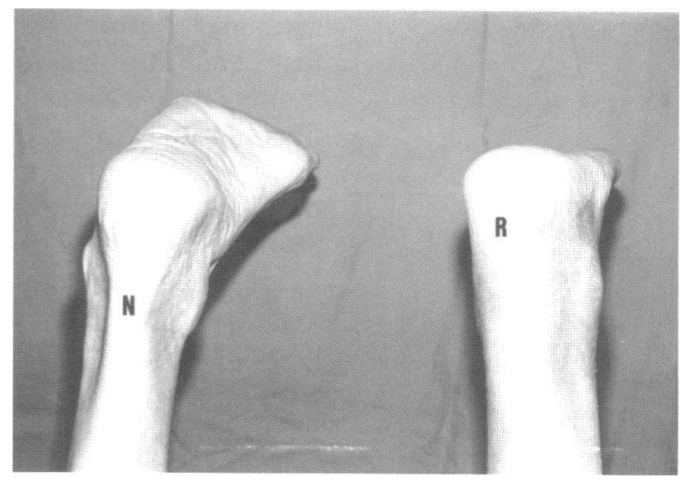

Figure 5 Matles'test. With the patient prone, the knees are flexed to $90^{\circ}$, and the position of the ankles and feet observed. If the foot on the affected side falls into neutral or dorsiflexion, an Achilles tendon rupture is diagnosed $(R)$. On the uninjured side, the foot remains in slight plantar flexion (N).

the tear surfaces of ruptured Achilles tendons. Fibronectin is a high molecular weight glycoprotein, normally located in basement membranes, and also present in a soluble form in plasma. Fibronectin binds more readily to denatured collagen than to normal collagen, ${ }^{68}$ suggesting that the presence of fibronectin on the surfaces of ruptured tendons may indicate pre-existing collagen denaturation.

\section{Presentation and diagnosis}

The typical patient with an Achilles tendon rupture generally presents to hospital with a classic history of sudden pain in the affected leg, often reporting that, at the time of injury, they thought that they had been struck by an object or kicked by a fellow sportsman. Some patients report an audible snap. They are often unable to weightbear and notice weakness or stiffness of the affected ankle. ${ }^{69}$ If they were playing sport, the injury tends to occur late in a game when they are fully warmed up. Indeed, Achilles tendon rupture is rarely associated with insufficient warm up. ${ }^{70}$ Patients with chronically ruptured Achilles tendons also tend to give a fairly typical history, often recalling only very minor or perhaps no trauma, and first noticing the injury as an inability to complete everyday tasks such as climbing stairs. ${ }^{31}$

On examination, there may be diffuse oedema and bruising, ${ }^{69}$ and a palpable gap may be felt along the course of the tendon ${ }^{69}$ unless the swelling is severe. The site of rupture is 


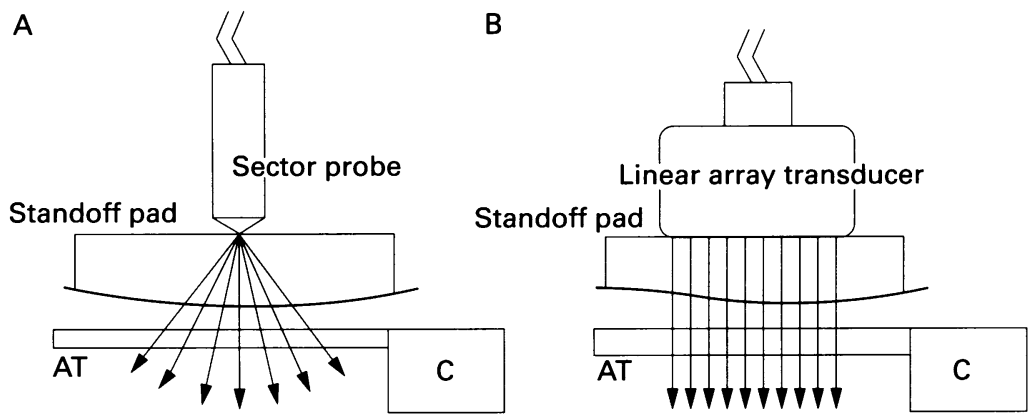

Figure 6 Comparison of sector-type and linear array ultrasound probes for imaging of the Achilles tendon. ( $A T=$ Achilles tendon, $C=$ calcaneus).

usually $2-6 \mathrm{~cm}$ proximal to the insertion of the tendon, ${ }^{21}$ the average distance measured intraoperatively being $4.78 \mathrm{~cm}$ in a recent large study. ${ }^{71}$

Diagnosis of Achilles tendon rupture should be straightforward. However, up to $25 \%$ are missed by the first examining doctor. ${ }^{72}$ There are a number of diagnostic signs and tests, both clinical and radiological, that the examiner may use to aid diagnosis.

\section{SIMMOND'S TEST}

Also known as the "calf squeeze test", it entails placing the patients prone on the examination couch, with their ankles clear of the couch, and squeezing the fleshy part of the calf. If the musculotendinous unit is intact, plantarflexion of the foot should occur. If the Achilles tendon is ruptured, plantarflexion does not occur (fig 4). The affected leg should be compared with the opposite leg. ${ }^{73} \mathrm{~A}$ false positive may occur in the presence of an intact plantaris, although this has not been scientifically proved. The Simmond's test works because of posterior bowing of the tendons of the calf muscles and, to a lesser extent, proximal displacement of the belly of gastrocnemius. ${ }^{74}$

The Simmond's test is often wrongly accredited to Thompson, who described the test jointly with Doherty in $1962,{ }^{75}$ five years after Simmond's paper was published in 1957. Later in 1962, Thomson described the test again in Acta Orthopaedica Scandinavica, ${ }^{76}$ this time without the aid of Doherty. ${ }^{77}$

\section{MATLES' TEST}

This test entails placing the patients prone on the examination couch, with their ankles clear of the end of the couch, and asking them to actively flex their knee to $90^{\circ}$. During flexion, the position of the ankle and feet should be observed. If the foot on the affected side falls into neutral or dorsiflexion, then an Achilles tendon rupture can be diagnosed (fig 5). ${ }^{78}$

\section{NEEDLE TEST}

This test entails inserting a hypodermic needle through the skin of the calf, medial to the midline and approximately $10 \mathrm{~cm}$ proximal to the insertion of the tendon. The needle is inserted until its tip is just within the substance of the tendon. The ankle is then alternately plantarflexed and dorsiflexed. If, when the ankle is dorsiflexed, the needle points distally, the tendon is intact in the portion distal to the needle. If the needle points proximally when the ankle is dorsiflexed, there is a loss of continuity between the needle and the tendon insertion. ${ }^{79}$

\section{COPELAND TEST}

This test entails inflating a sphygmomanometer cuff around the mid-calf of the affected leg while the patient is lying prone. The cuff is inflated to $100 \mathrm{~mm} \mathrm{Hg}$ with the foot in plantarflexion. The foot is then dorsiflexed, and if the pressure rises to approximately 140 $\mathrm{mm} \mathrm{Hg}$ then the musculotendinous unit is intact. If, however, the pressure stays at around $100 \mathrm{~mm} \mathrm{Hg}$ then an Achilles tendon rupture may be diagnosed. ${ }^{80}$

Recent work in our unit, with a large group of patients with Achilles tendon ruptures, ascertained that there was no statistically significant difference in predictive value between the above mentioned tests (Maffulli N, unpublished data ). The diagnosis of Achilles tendon rupture is certain if the result of at least two of these tests were positive.

\section{Tendon imaging in diagnosis \\ PLAIN RADIOGRAPHY}

Some signs that may be observed on lateral radiographs of the ankle are said to indicate that the Achilles tendon has been ruptured. The first such sign involves the contours of Kager's triangle, ${ }^{81}$ the fat filled space bounded by the margins of the Achilles tendon, calcaneus, and deep toe flexors. When the Achilles tendon is ruptured, this triangle loses its regular configuration. Toygar's $\operatorname{sign}^{82}$ entails measuring the angle of the posterior skin surface curve seen on plain radiographs. An angle of $130^{\circ}$ to $150^{\circ}$ would indicate Achilles tendon rupture. Toygar himself considered an angle of $130^{\circ}$ to $150^{\circ}$ accompanied by displacement of Kager's triangle to be so characteristic of Achilles tendon rupture as virtually suffice for diagnosis. Arner and Lindholm ${ }^{83}$ studied the plain radiographic changes seen with Achilles tendon rupture. They stated that "a curving away from the bone of the posterior tendon contour between its insertion and the upper margin of the calcaneus combined with unimpaired contour, and forward deviation of the anterior tendon contour proximal to the calcaneus" were the radiographic changes most likely to be associated with Achilles tendon rupture. ${ }^{83}$

Clinical diagnosis is usually sufficient for acute ruptures of the Achilles tendon. Ruptures that are more longstanding may be harder to diagnose because of associated tissue swelling, etc. Magnetic resonance imaging (MRI) and real time high resolution ultrasonography (US) provide an adjunct to clinical diagnosis, and they are more sensitive than soft tissue radiography or xeroradiography. ${ }^{84}$

\section{MRI}

On MRI, the normal Achilles tendon is seen as an area of low signal intensity on all pulse sequences used. The tendon is well delineated by the high signal intensity of the fat pad of Kager's triangle. ${ }^{85}$ Any increase in signal intensity within the tendon should be regarded 

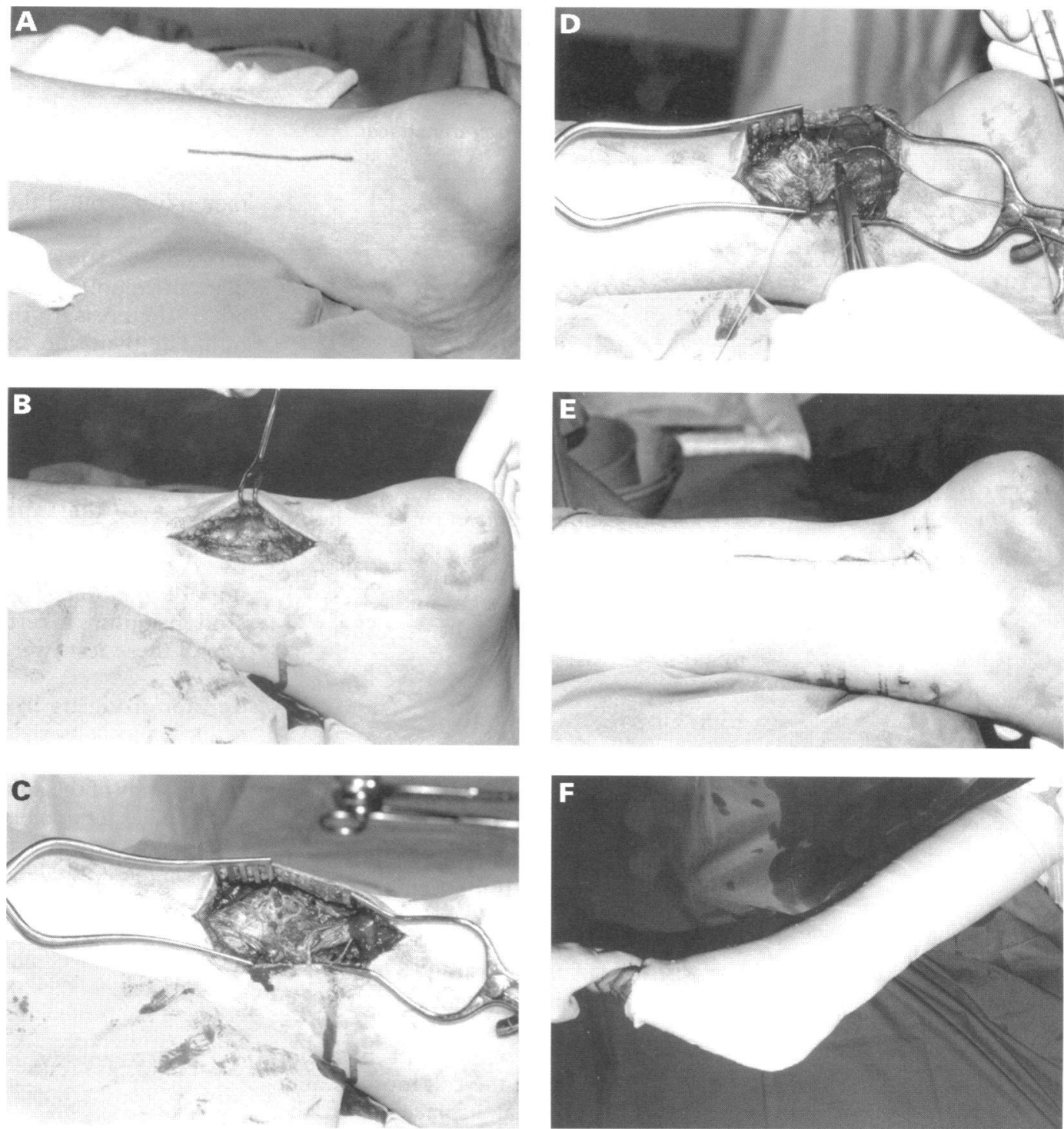

Figure 7 (A) An 8 to $10 \mathrm{~cm}$ longitudinal incision is placed just medial to the medial border of the tendon, centred on the palpable gap. (B) The subcutaneous fat is divided by sharp dissection, with no undermining of the skin edges. The paratenon is visualised, then incised longitudinally. If the paratenon remains viable then it may be attached to the subcutaneous fat with temporary sutures so that it does not interfere with the tendon itself during the procedure. (C) The ruptured tendon is exposed, demonstrating the typical horse tail appearance. Frayed ends are not routinely freshened, but this may be necessary in patients presenting later. Two self retaining retractors are positioned to expose the tendon. (D) The ankle is plantarflexed to aid apposition of tendon ends. $A$ single Kessler suture is passed through the proximal and distal stumps of the tendon. A running circumferential suture is then inserted using a finer material. The repair is often too thick to facilitate closure of the paratenon, in which case it is simply laid over the repair. (E) Interrupted fine reabsorbable sutures are used to close the subcutaneous fat, and the skin is closed with fine reabsorbable sutures inserted into the subcuticular layer. (F) The wound is supported with steristrips, and a routine gauze and wool dressing is applied. A below knee cast in gravity equinus is then applied.

as abnormal. ${ }^{86}$ Axial and saggital plane $\mathrm{T} 1$ and T2 weighted images should be used to evaluate suspected Achilles tendon ruptures. T1 weighted images show complete ruptures of the Achilles tendon as disruptions of the signal within the tendon. T2 weighted images are the method of choice for MRI diagnosis of Achilles tendon ruptures. The rupture is demonstrated as a generalised increase in signal intensity, and the oedema and haemorrhage at the site of rupture is seen as an area of high signal intensity. ${ }^{85}$

\section{ULTRASOUND}

US of the Achilles tendon using linear probes produces a dynamic and panoramic image of the tendon. ${ }^{85}$ The appearance of the tendon varies with the type of transducer used and the angle of the ultrasound beam with respect to the tendon. ${ }^{87}$ High frequency probes of 7.5-10 $\mathrm{MHz}$ provide the best resolution but are limited by a short focusing distance, usually not exceeding 3-4 cm. ${ }^{88}$ The Achilles tendon is composed of longitudinally arranged collagen bundles, which act as reflectors of the ultrasound beam. The US probe should be held at right angles to the tendon to ensure that an optimal amount of ultrasonic energy is returned to the transducer ${ }^{87}$ and to avoid artefacts. ${ }^{88}$ Linear array transducers are therefore better suited than sector-type transducers, which produce excess obliquity of the US beam at the edges (fig 6). It may also be necessary to use a synthetic gel spacer or standoff pad, increasing the definition of the surface echoes and permitting a suitable support. ${ }^{89}$ 
Table 5 Surgical repair of Achilles tendon rupture: complications and re-ruptures (note: re-rupture rate is included in complication rate)

\begin{tabular}{lccc}
\hline Authors & Cases & $\begin{array}{l}\text { Number (\%) of } \\
\text { complications }\end{array}$ & $\begin{array}{l}\text { Number (\%) of } \\
\text { re-ruptures }\end{array}$ \\
\hline Arner and Lindholm $1959^{64}$ & 86 & $21(24.4)$ & $4(4.6)$ \\
Gilles and Chalmers $1970^{102}$ & 6 & $1(16.7)$ & $0(0)$ \\
Kvist and Andersen $1972^{45}$ & 37 & $7(18.9)$ & $1(2.7)$ \\
Inglis et al $1976^{72}$ & 44 & $2(4.5)$ & $0(0)$ \\
Jacobs et al $1978^{121}$ & 26 & $5(19.2)$ & $0(0)$ \\
Quigley and Scheller $1980^{123}$ & 40 & $7(17.5)$ & $2(5)$ \\
Nistor $1981^{104}$ & 45 & $4(8.9)$ & $2(4.4)$ \\
Kellam et al $1985^{122}$ & 68 & $9(13.2)$ & $2(2.9)$ \\
Carden et al $1987^{3}$ & 56 & $6(10.7)$ & $2(3.6)$ \\
Aldam $1989^{108}$ & 41 & $2(4.9)$ & $1(2.4)$ \\
Sejberg et al $1990^{124}$ & 81 & $17(21.1)$ & $3(3.7)$ \\
Cetti et al $1993^{29}$ & 56 & $15(26.8)$ & $3(5.4)$ \\
Saw et al $1993^{110}$ & 19 & $4(21.1)$ & $0(0)$ \\
Krueger-Franke et al $1995^{71}$ & 365 & $55(15.1)$ & $9(2.5)$ \\
Soldatis et al $1997^{106}$ & 23 & $2(8.7)$ & $0(0)$ \\
Total & 993 & $157(15.8)$ & $29(2.9)$ \\
\hline
\end{tabular}

A normal Achilles tendon appears sonographically as a hypoechogenic, ribbon-like image within two hyperechogenic bands. Tendon fascicles can be observed as alternate hypo- and hyper-echogenic bands, which are separated when the tendon is relaxed and more compact when it is under strain. ${ }^{89}$ Sonographically, there are no differences between the left and right Achilles tendons, nor any differences between sexes, except that tendons in men are slightly thicker than those in women. ${ }^{90}$ Rupture of the Achilles tendon is seen on US as an acoustic vacuum with thick, irregular edges. ${ }^{89}$ Campani et $a l^{11}$ conducted 170 US examinations for various lower limb traumas. The highest percentage of positive findings was in the Achilles tendon $(75 \%)$, compared with only $38 \%$ for lesions in the thigh. Maffulli et a $l^{22}$ have shown that US is a suitable tool for assessing tendon structure after surgical repair. US cannot only give a morphological picture of a tendon, but can be used to study its biomechanical properties. $^{93}$

\section{Treatment}

Many techniques and procedures have been described for the treatment of a ruptured Achilles tendon. Such techniques can be grouped under three headings: surgical, percutaneous, and non-surgical. Controversy abounds regarding which is the best method of treatment as there is no agreed protocol, and the choice of treatment regimens still lies largely with the preference of the surgeon and the patient.

\section{SURGICAL TREATMENT}

Various surgical techniques have been used to repair ruptured Achilles tendons. These range from simple end to end suturing by Bunnell or Kessler type sutures (fig 7), to more complex repairs using fascial reinforcement or tendon grafts. ${ }^{94}$ Artificial tendon implants have also been performed, using material such as absorbable polymer-carbon fibre composite, ${ }^{95}$ Marlex mesh, ${ }^{96}$ and a collagen tendon prosthesis. ${ }^{98}$ Simple end to end suturing techniques have been modified by the use of materials such as Dacron vascular graft, which is passed through the tendon in a Bunnell-type fashion..$^{99}$ Canine experiments have shown that Dacron supports the growth of fibrous tissue. ${ }^{100}$ It also facilitates the approximation of tendon ends but causes less tension of the repair site than standard sutures. ${ }^{99}$ However, as maturation of collagen may be dependent on a tensional stimulus, ${ }^{101}$ lack of tension on the repair site may not be advantageous.

The main opponents of surgical repair cite the high complication rate as the main disadvantage. ${ }^{36102-105}$ Arner and Lindholm ${ }^{64}$ reported a series of 86 operative repairs of Achilles tendon ruptures in which there were 21 complications $(24.4 \%)$, including two cases of deep vein thrombosis, one of which resulted in pulmonary embolism and death, three wound infections, 11 cases of wound necrosis, and four re-ruptures. More recent reports have had a much lower complication rate. Soldatis $e t$ $a l^{106}$ reported a series of 23 surgically treated patients, in which the only complications were two cases of delayed wound healing. It is probable that the complication rate has fallen because of greater surgical experience, and improved surgical technique. Wound problems should not be unexpected when surgical repair is used, as the classic longitudinal incision passes through poorly perfused skin. ${ }^{107}$ Aldham ${ }^{108}$ used a transverse incision just distal to the gap in the tendon. In his 41 patients there was only one case of wound breakdown. After surgical repair, the leg is immobilised in a cast for four to six weeks. ${ }^{29}$ Some workers have advocated the use of a functional orthosis after just several days of cast immobilisation. This permits unlimited plantarflexion, but restricts dorsiflexion, and is designed to help prevent atrophy of the triceps surae. ${ }^{109} 110$ Table 5 outlines some of the studies on surgical repair, and shows the comparatively high overall complication rate, and low re-rupture rate.

\section{PERCUTANEOUS REPAIR}

The percutaneous technique for repair of ruptured Achilles tendons was first described by $\mathrm{Ma}$ and Griffith. ${ }^{111}$ They developed this technique because of their dissatisfaction with the complications of surgical and non-surgical techniques and stated that this technique minimised many of the complications of surgical repair, while restoring tendon continuity and length. The technique entails producing six small stab incisions along the medial and lateral borders of the tendon, then passing a suture through the tendon via these incisions (fig 8). Ma and Griffith reported on a small series of 18 patients treated by this technique, in which there were only two minor, noninfectious skin complications and no reruptures. Rowley and Scotland ${ }^{112}$ described 24 cases of rupture of the Achilles tendon, 14 treated by equinus cast alone, and 10 treated by the percutaneous technique described above. There was one case on entrapment of the sural nerve in the sutured group, but no other complications were encountered. Plantar flexion strength was measured in both groups according to a method described by Gilles and Chalmers. ${ }^{102}$ It was noted that patients in the sutured group were more likely to have a return to near normal plantar flexion strength, and patients in this group were also perceived to 

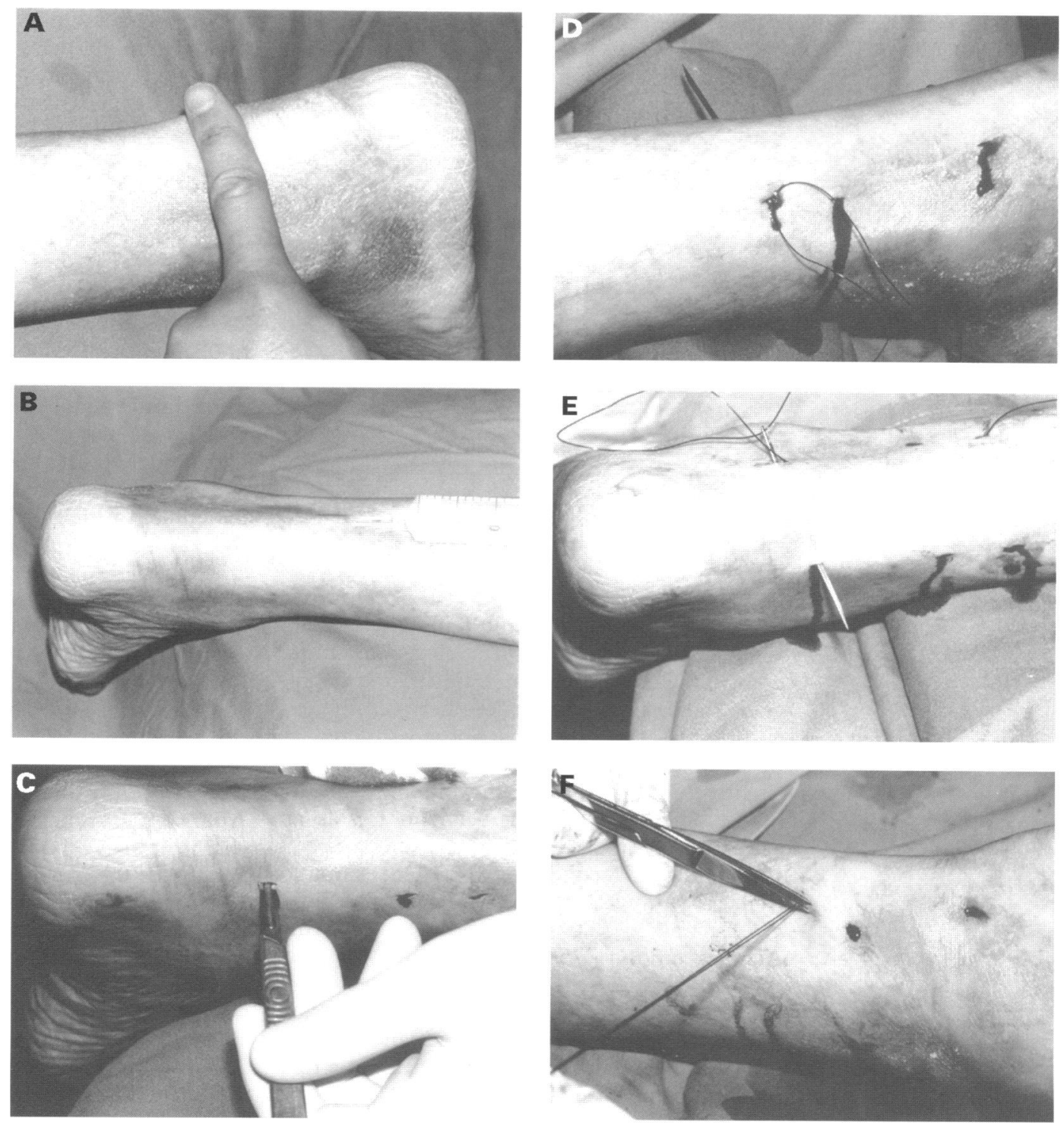

Figure 8 (A) Gap in tendon is identified by palpation. (B) 1\% Lignocaine with adrenaline 1:100 000 is infiltrated along the medial and lateral borders of the tendo Achilles. (C) Creating the stab incisions along the medial and lateral borders of the tendon, through which the sutures will be passed. (D) Suture passed into the proximal lateral stab incision and through the proximal portion of the ruptured tendon. (E) Suture passed into distal lateral stab incision and through the distal portion of the ruptured tendon. $(F)$ Suture is tied and cut short, then pushed subcutaneously. The stab incisions may be closed with steristrips, or simply covered with gauze. A routine gauze and wool bandage is applied, then the leg is cast in a below knee gravity equinus cast.

return to activity sooner the group treated by cast alone. Other authors have not had so much success with this technique. Klein et $a l^{113}$ reported on a series of 38 patients in which sural nerve entrapment occurred in $13 \%$. An in vitro comparison of surgical and percutaneous techniques by Hockenbury and Johns ${ }^{114}$ showed that repair of Achilles tendons by a percutaneous technique was up to $50 \%$ weaker than surgical end to end suturing. They also noted that there was a high risk of sural nerve entrapment using this technique, and that the tendons ends were not anatomically juxtaposed. Bradley and Tibone ${ }^{115}$ found that the thickness of percutaneously repaired Achilles tendons was significantly less than that of surgically repaired ones. Patients who had their Achilles tendons repaired percutaneously were much less likely to complain of heel pain. ${ }^{115}$ Table 6 shows some of the results of studies using the percutaneous technique. The figures demonstrate the higher re-rupture rate associated with percutaneous repair.
NON-SURGICAL TREATMENT

There are two forms of non-surgical treatment for rupture of the Achilles tendon. The first consists essentially of supervised neglect. This is used for elderly patients with longstanding ruptures discovered by chance. These patients are warned that, if the symptoms caused by their Achilles tendon rupture worsen, they may require an operation. They are reviewed at regular intervals, but will usually require no further treatment (Maffulli $\mathrm{N}$, unpublished data).

The second form of non-surgical treatment is by plaster cast immobilisation, usually for a period of six to eight weeks. ${ }^{29}$ Some workers have advocated that immobilisation alone produces a similar, if not better result than surgery. ${ }^{3}{ }^{102-105}$ Lea and Smith ${ }^{103}$ reported on a series of 55 spontaneously ruptured Achilles tendons that were treated by eight weeks of immobilisation. They had seven re-ruptures $(12.7 \%)$, and 52 of the 55 patients were satisfied with the result. Lea and Smith 
Table 6 Percutaneous repair of Achilles tendon rupture: complications and re-ruptures (note: re-rupture rate is included in complication rate)

\begin{tabular}{llll}
\hline Authors & Cases & $\begin{array}{l}\text { Number (\%) of } \\
\text { complications }\end{array}$ & $\begin{array}{l}\text { Number (\%) of } \\
\text { re-ruptures }\end{array}$ \\
\hline Ma and Griffiths $1977^{111}$ & 18 & $2(11.1)$ & $0(0)$ \\
Rowley and Scotland 1982 & 112 & $1(10)$ & $0(0)$ \\
Bradley and Tibone $1990^{115}$ & 12 & $2(16.7)$ & $2(16.7)$ \\
Klein et al $1991^{113}$ & 38 & $8(21.1)$ & $3(7.9)$ \\
Total & 78 & $13(16.7)$ & $5(6.4)$ \\
\hline
\end{tabular}

Table 7 Non-surgical repair of Achilles tendon rupture: complications and re-ruptures (note: re-rupture rate is included in complication rate)

\begin{tabular}{lccc}
\hline Authors & Cases & $\begin{array}{l}\text { Number (\%) of } \\
\text { complications }\end{array}$ & $\begin{array}{l}\text { Number (\%) of } \\
\text { re-ruptures }\end{array}$ \\
\hline Gilles and Chalmers $1970^{102}$ & 7 & $1(14.3)$ & $1(14.3)$ \\
Lea and Smith $1972^{103}$ & 55 & $7(12.7)$ & $7(12.7)$ \\
Inglis et al $1976^{72}$ & 23 & $9(39)$ & $9(39)$ \\
Person and Wredmark $1979^{116}$ & 20 & $9(45)$ & $7(35)$ \\
Carden et al $1987^{3}$ & 76 & $3(3.9)$ & $1(1.3)$ \\
Total & 181 & $29(16.0)$ & $25(13.8)$ \\
\hline
\end{tabular}

believed that these results indicated that surgical treatment was not necessary. They stated that "the success of this method (non-surgical treatment) evolves from the fact that the Achilles tendon, when ruptured, sectioned or removed, will regenerate itself". ${ }^{103}$ This statement totally ignores the fact the one of the main goals of treatment of Achilles tendon rupture is to prevent tendon lengthening. Nonsurgical treatment cannot usually achieve this goal. ${ }^{94}$ Persson and Wredmark ${ }^{116}$ reported on a series of 20 patients with Achilles tendon ruptures treated non-surgically. There were seven re-ruptures in this group (35\%), and only 13 of the patients $(65 \%)$ were satisfied with the result. They concluded that, although the function after non-surgical repair was generally good, the high incidence of re-rupture was unacceptable. Stein and Luekens ${ }^{105}$ stated that, when Achilles tendon rupture occurs, the paratenon remains intact. They found experimentally that stripping of the paratenon during surgery reduced the amount of reactive tissue that was later seen at the site of injury. They suggested that surgical repair of ruptured Achilles tendons should be avoided as the paratenon provided a valuable blood supply to the damaged tendon. Table 7 shows the high complication and re-rupture rate associated with non-surgical management of Achilles tendon rupture.

Work by Häggmark and Eriksson ${ }^{117}$ shows that long immobilisation, such as that occurring during non-surgical treatment for Achilles tendon rupture, results in a significant decrease in calf circumference. As the cross sectional area of a muscle is directly related to the force that the muscle can develop, ${ }^{118}$ long periods of immobilisation will result in a significant loss of calf muscle strength. The soleus muscle seems to be particularly susceptible to immobilisation, while the gastrocnemius is less affected being a biarticular muscle, and therefore is still stretched to a certain extent, even when the leg is immobilised below the knee. Human soleus contains a high proportion of type I muscle fibres. ${ }^{17}$ Type I muscle fibres are particularly susceptible to atrophy if the muscle is immobilised, as they are responsible for postural tone, and are continually activated while standing. ${ }^{119}$ When the leg is immobilised, the muscle spindle relaxes, and afferent impulses to type I fibres cease, thus causing them to atrophy. Obviously, problems resulting from immobilisation occur after surgical and percutaneous repair too, but not to the same extent. Häggmark et $a l^{120}$ compared the degree of decrease in calf circumference after surgical and non-surgical repair of Achilles tendon ruptures. They found that, while there was a significant decrease in the non-surgically treated group, the surgically treated group showed no significant decrease. Patients with surgical or percutaneous repairs spend less time in plaster, ${ }^{29}$ and on the whole are often more serious athletes who will comply well with treatment regimens. The lack of tension on the immobilised musculotendinous unit is an important factor in the development of calf atrophy, and, if optimal results are required from a repair of a ruptured Achilles tendon, then the repair should be put under as much tension as possible, ${ }^{117}$ and the casts should be changed regularly, decreasing the angle of plantarflexion as much as possible each time.

SURGICAL VERSUS NON-SURGICAL TREATMENT Although there are a number of reports that compare the results of surgical treatment of Achilles tendon rupture with that of nonsurgical treatment, only a few well controlled, prospective randomised trials have been conducted (table 8). Gilles and Chalmers ${ }^{102}$ objectively measured the plantarflexion strength of patients with Achilles tendon ruptures treated surgically and non-surgically. They found that there was little difference between the two groups, and concluded that the results of surgery were not sufficiently superior to warrant the extra risk that accompanies a general anaesthetic. Inglis et $a l^{2}$ followed up a group of 67 patients, 44 of whom were treated surgically and 23 non-surgically. There were no re-ruptures in the surgically treated group, but nine re-ruptures (39\%) occurred in the nonsurgically treated group. Strength testing showed that surgically treated patients had superior strength, power, and endurance. The authors concluded that surgery was the treatment option of choice. Nistor ${ }^{104}$ conducted a prospective randomised trial along similar lines. He had a group of 105 patients, 45 of whom had surgical treatment, and 60 who had non-surgical treatment. The re-rupture rate of Nistor's surgical group was $4.4 \%$ compared with $8.3 \%$ for the non-surgical group. However, there were a large number of secondary complications in the surgical group. Patients treated non-surgically were found to have less absence from work, less ankle stiffness, and similar strength to the surgical group. Nistor concluded that, because there were only minor differences between the two groups, nonsurgical treatment was the method of choice. Carden $e t a l^{3}$ compared the results of surgical and non-surgical treatment in patients presenting to hospital less than 48 hours after injury with those presenting greater than 48 hours. In total, they treated 76 patients non-surgically, 
Table 8 Randomised controlled trials of repair of Achilles tendon rupture (note: re-rupture rate is included in complication rate)

\begin{tabular}{lccc}
\hline & Cases & $\begin{array}{l}\text { Number (\%) of } \\
\text { complications }\end{array}$ & $\begin{array}{l}\text { Number (\%) of } \\
\text { re-ruptures }\end{array}$ \\
\hline Surgically managed patients & 45 & $4(8.9)$ & $2(4.4)$ \\
$\quad$ Nistor $1981^{104}$ & 56 & $5(9)$ & $3(5)$ \\
$\quad$ Cetti et al $1993^{29}$ & 101 & $9(8.9)$ & $5(5.0)$ \\
$\quad \begin{array}{l}\text { Total } \\
\text { Non-surgically managed patients }\end{array}$ & 60 & $5(8.3)$ & $5(8.3)$ \\
$\quad$ Nistor $1981^{104}$ & 55 & $9(16.3)$ & $7(12.7)$ \\
$\quad$ Cetti et al $1993^{29}$ & 115 & $14(12.2)$ & $12(10.4)$ \\
Total & & & \\
\hline
\end{tabular}

and 56 surgically. The overall complication rate in the non-surgical group was $3.9 \%$ compared with $16.6 \%$ for the surgical group. Subjective results were also better in the non-surgically treated group. They concluded that patients presenting less than 48 hours after injury should be treated non-surgically by eight weeks of cast immobilisation, whereas patients presenting greater than one week after injury should be treated surgically. Cetti et al ${ }^{29}$ also conducted a prospective randomised trial of surgical versus non-surgical treatment Their study group consisted of 111 patients, 56 with operative repairs and 55 with non-operative repairs. They compared complication rates and re-rupture rates between the two groups. Surgical treatment had a complication rate of $9 \%$ and a re-rupture rate of $5 \%$ compared with $16 \%$ and $15 \%$ respectively for non-surgical treatment. These results, however, were not statistically significant. They also conducted a review of Achilles tendon rupture literature, and identified 4597 ruptures. Making the same comparisons as above, surgical treatment was found to have significantly lower complication rates and re-rupture rates than non-surgical treatment. They concluded that surgical treatment was the method of choice, but nonsurgical treatment was an acceptable alternative. In summary, if optimal performance is required of the ruptured Achilles tendon, then surgery is the treatment of choice. It should be used in athletes and in patients who are particularly active. Percutaneous repair is useful for patients who do not wish to undergo an open surgical repair, possibly for cosmetic reasons, or perhaps because they view an open surgical repair as a more serious procedure. Many patients undergo percutaneous repair with only a local anaesthetic, and are able to return home the same day. ${ }^{110}$ Conservative treatment should be reserved for older patients who are unlikely to achieve any major benefit from a surgical procedure, or for those patients who view surgery as an unnecessary risk.

\section{Conclusions}

It is perhaps surprising to people who are not involved in this field that the aetiology of what would seem to be a simple condition is, in fact, rather complicated. Despite extensive investigation, few answers about the aetiology of Achilles tendon rupture have been found. The lack of study of human tissue is an obvious problem, but it is difficult to see how this could be overcome.

The type of treatment for acute Achilles tendon ruptures remains largely with the prefer- ence of individual surgeons. It is evident that open surgical repair produces superior functional results, but may have significant postoperative complications. Non-surgical treatment may result in a poorer functional result, but the problems of postoperative complications are avoided.

If the studies that report increasing incidence of Achilles tendon rupture are correct, then the field of Achilles tendon surgery will become an increasingly important one. Future developments may include the routine use of adhesives in tendon surgery. An understanding of the role that cytokines play in tendon healing may lead to the advent of new treatments. However, such novel treatments are unlikely to be in routine clinical use for some time.

Part of this work was supported by the Wellcome Trust.

1 O'Brien $M$. Functional anatomy and physiology of tendons. Clin Sports Med 1992;11:505-20.

2 Shampo M A, Kyle R A. Medical mythology: achilles. Mayo Clin Proc 1992;67:651.

3 Carden D G, Noble J, Chalmers J, Lunn P, Ellis J. Rupture of the calcaneal tendon: the early and late management. $\mathcal{F}$ Bone foint Surg 1987;69-B:416-20.

4 Carlstedt C A. Mechanical and chemical factors in tendon healing:effects of indomethacin and surgery in the rabbit. Acta Orthop Scand 1987;58 (suppl 224):1-75.

5 Davidson R G, Taunton J E. Achilles tendinitis. Med Sports Sci 1987;23:71-9.

6 Stein S R, Luekens C A. Closed treatment of Achilles tendon ruptures. Orthop Clin N Am 1976;7:241-6.

7 Cummins E J, Anson B J, Carr B W, Wright R, Hauser E D $W$. The structure of the calcaneal tendon (of Achilles) in relation to orthopaedic surgery: with additional observarelation to orthopaedic surgery: with additional observa-
tions on the plantaris muscle. Surg Gynaecol Obstetr tions on the plat
$1946 ; 83: 107-6$.

8 Williams P L, Warwick R, eds. Gray's anatomy. 36th ed. Edinburgh: Churchill Livingstone, 1980: 608 .

9 Clain M R, Baxter D E. Achilles tendinitis. Foot Ankle 1992; 13:482-7

10 Alexander R McN, Bennet-Clark H C. Storage of elastic strain energy in muscle and other tissues. Nature 1977;265: $114-7$.

11 Rufai A, Ralphs R, Benjamin M. Structure and histopathology of the insertional region of the human Achilles tendon. F Orthop Res 1995;13:585-93.

12 Gross M T. Chronic tendinitis: pathomechanics of injury, factors affecting the healing response, and treatment. $\mathcal{f}$ Orthop Sports Phys Ther 1992;16:248-61.

13 Hess G P, Cappiello W L, Poole R M, Hunter S C. Prevention and treatment of overuse tendon injuries. Sports Med 1989;8:371-84.

14 Coombs R R H, Klenerman L, Narcisi P, Nichols A, Pope F M. Collagen typing in Achilles tendon rupture. $\mathcal{F}$ Bone foint Surg 1980;62-B:258.

15 Ross M H, Romrell L J. Connective tissue. In: Ross MH, Romrell J, eds. Histology: $A$ text and atlas. 2 nd ed. Baltimore: Williams \& Wilkins, 1989: 85-116.

16 Squier C A, Magnes C. Spatial relationships between fibroblasts during the growth of rat tail tendon. Cell Tissue Res 1983;234:17-29.

17 Postacchini F, Ippolito E, Puddu G, Martino C. Intracellular collagen fibres in regenerating tendon. Ricerca iu Clinica e iu Laboratorio 1981;11:343-7.

18 Schmidt-Rolfing B, Graf J, Schneider U, Neithard F U. The blood supply of the Achilles tendon. Int Orthop 1992;16: 29-31.

19 Birk D E, Trelstad R L. Extracellular compartments in matrix morphogenesis: collagen fibril, bundle and lamellar formation by corneal fibroblasts. F Cell Biol 1984;99:202433.

20 Mayer L. The physiological method of tendon transplantation. Surg Gynaecol Obstetr 1916;22:183-97.

21 Håstad K, Larsson L-G, Lindholm Á. Clearance of radiosodium after local deposit in the Achilles tendon. Acta Chir dium after local deposit

22 Lagergren C, Lindholm A. Vascular distribution in the Achilles tendon: An angiographic and microangiographic Achilles tendon: An angiographic and

23 Åström M, Westlin N. Blood flow in the human Achilles tendon assessed by laser doppler flowmetry. $\mathrm{f}$ Orthop Res tendon assessed by

24 Fukashiro S, Komi P, Järvinen $M$, Miyashita $M$. In vivo Fukashiro S, Komi $\mathrm{P}$, Järvinen $M$, Miyashita $M$. In vivo
Achilles tendon loading during jumping in humans. Eur $\mathcal{f}$ Appl Physiol 1995;71:453-8.

25 Komi P V, Fukashiro S, Järvinen M. Biomechanical loading of Achilles tendon during normal locomotion. Clin Sports Med 1992;11:521-31

26 Ippolito E, Natali P G, Postacchini F, Accinni L, de Martino C. Morphological, immunochemical, and biochemical study of rabbit Achilles tendon at various ages. $\mathcal{f}$ Bone foint Surg 1980;62-A:583-598. 
27 Leppilahti J, Puranen J, Orava S. Incidence of Achilles tendon rupture. Acta Orthop Scand 1996;67:277-9.

28 Postacchini F, Puddu G. Subcutaneous rupture of the Achilles tendon. Int Surg 1976; 61:14-8.

29 Cetti R, Christiansen S-E, Ejsted R, Jensen N M, Jorgensen $U$. Operative versus nonoperative treatment of Achilles tendon rupture: A prospective randomized study and
review of the literature. $A m \mathcal{F}$ Sports Med 1993;21:791-9.

30 Puddu G, Ippolito E Postacchini F. A classification of Achilles tendon disease. Am $\mathcal{F}$ Sports Med 1976;4:145-50.

31 Hattrup S J, Johnson K A. A review of ruptures of the Achilles tendon. Foot Ankle 1985;6:34-8.

32 Boyden E M, Kitaoka H B, Cahalan T D, An K-N. Late versus early repair of Achilles tendon rupture: clinical and biomechanical evaluation. Clin Orthop 1995;317:150-8.

33 Jozsa L, Kvist M, Balint J B, et al. The role of recreational sport activity in Achilles tendon rupture: A clinical, patho-
anatomical, and sociological study of 292 cases. $A m ~$ Sports Med 1989;1 17:338-3.

34 Jozsa L, Balint J B, Kannus P, Reffy A, Barzo M. Distribution of blood groups in patients with tendon rupture: An analysis of 832 cases. $\mathcal{f}$ Bone foint Surg 1989;71-B:272-4

35 Kujala U M, Järvinen $M$, Natri $A$, et al. ABO blood groups and musculoskeletal injuries. Injury 1992;23:131-3.

36 Arner O, Lindholm A, Orell S R. Histologic changes in subcutaneous rupture of the Achilles tendon: A study of 74 cases. Acta Chir Scand 1959;116:484-90.

37 Dodds W N, Burry H C. The relationship between Achilles tendon rupture and serum uric acid level. Injury 1984;16: 94-5.

38 Dent C M, Graham G P. Osteogenesis imperfecta and Achilles tendon rupture. Injury 1991;22:239-40.

39 Clement D B, Taunton J E, Smart G W. Achilles tendinitis and peritendinitis: etiology and treatment. Am $\mathcal{F}$ Sports Med 1984;12:179-84

40 Newham D M, Douglas J G, Legge J S, Friend J A R. Achilles tendon rupture: an underrated complication of corticosteriod treatment. Thorax 1991;46:853-4.

41 Royer R J, Pierfitte C, Netter P. Features of tendon disorders with fluoroquinolones. Therapie 1994;49:75-6.

42 McMaster P E. Tendon and muscle ruptures: clinical and experimental studies on the causes and location of experimental studies on the causes and location of

43 Kuwada G T. Diagnosis and treatment of Achilles tendon rupture. Clin Podiatr Med Surg 1995;12:633-52.

44 Davidsson L, Salo M. Pathogenesis of subcutaneous Achilles tendon ruptures. Acta Chir Scand 1969;135:209-12.

45 Kvist-Kristiansen J, Thestrup Andersen P. Rupture of the Achilles tendon: A series and review of the literature. $f$ Trauma 1972;12:794-7.

46 Fox J M, Blazina M E, Jobe F W, et al. Degeneration and rup ture of the Achilles tendon. Clin Orthop 1975;107:221-4.

47 Balasubramaniam P, Prathap K. The effect of injection of hydrocortisone into rabbit calcaneal tendons. $\mathcal{f}$ Bone foint hydrocortisone into rabbit
Surg 1972;54-B:729-34.

48 DiStefano V J, Nixon J E. Ruptures of the Achilles tendon. f Sports Med 1973;1:34-7.

49 Unverfirth L J, Olix M L. The effect of local steroid injections on tendon. F Bone foint Surg 1973;55-A:1315.

50 Kennedy J C, Baxter Willis R. The effects of local steroid injections on tendons: a biomechanical and microscopic correlative study. Am $\mathcal{F}$ Sports Med 1976;4:11-2

51 McWhorter J W, Francis R S, Heckmann R A. Influence of local steroid injections on traumatized tendon properties: $A$ biomechanical and histological study. Am $\mathcal{f}$ Sports Med 1991;19:435-9.

52 Mahler F, Fritschy D. Partial and complete ruptures of the Achilles tendon and local corticosteroid injections. $\mathrm{Br} \mathcal{F}$ Sports Med 1992;26:7-14.

53 Szarfman A, Chen M, Blum M D. More on fluoroquinolone antibiotics and tendon rupture. $N$ Engl f Med 1995;332: 193.

54 British Medical Association, Royal Pharmaceutical Society of Great Britain. British National Formulary. London: September 1996: 259.

$55 \mathrm{Ker}$ R F. Dynamic tensile properties of the plantaris tendon of sheep (ovis aries). F Exp Biol 1981;93:283-302.

56 Wilson A M. Goodship A E. Exercise-induced hyperthermia as a possible mechanism for tendon degeneration. $f$ Biomech 1994;27:899-905.

57 Arancia G. Trovalusci C, Mariutti G, Mondovi B. Ultrastructural changes induced by hyperthermia in Chinese hamster V79 fibroblasts. Int $\mathcal{F}$ Hyperthermia 1989 5:341-50.

58 Barfred T [a]. Kinesiological comments on subcutaneous rupture of the Achilles tendon. Acta Orthop Scand 1971;42 rupture of

59 Barfred T [b]. Experimental rupture of the Achilles tendon comparison of experimental ruptures in rats of different ages and living under different conditions. Acta Orthop Scand 1971;42:406-28.

60 Barfred T [c]. Experimental rupture of the Achilles tendon: comparison of various types of experimental rupture in comparison of various types of experi
rats. Acta Orthop Scand 1971;42:528-43.

61 Williams J G P. Achilles tendon lesions in sport. Sports Med 1986;3:114-35

62 Inglis A E, Sculco T P. Surgical repair of ruptures of the tendo Achillis. Clin Orthop 1981;156:160-9.

63 Knörzer E, Folkhard W, Geercken W, et al. New aspects of the aetiology of tendon rupture.: An analysis of timeresolved dynamic-mechanical measurements using synchotron radiation. Arch Orthop Trauma Surg1986;105:113-20.
64 Arner O, Lindholm A. Subcutaneous rupture of the Achilles tendon: A study of 92 cases. Acta Chir Scand 1959; (suppl 239): $1-51$

65 Kannus P, Josza L. Histopathological changes preceding spontaneous rupture of a tendon. I Bone foint Surg 1991;73-A: $1507-25$.

66 Leadbetter W B. Cell-matrix response in tendon injury. Clin Sports Med 1992;11:533-78.

67 Jozsa L, Lehto M, Kannus P, et al. Fibronectin and laminin in Achilles tendon. Acta Orthop Scand 1989;60:469-71.

68 Engvall E, Ruooslahti E, Miller E J. Affinity of fibronectin to collagens of different genetic types and to fibrinogen. $\mathcal{F}$ Exp Med 1978;147: 158

69 DiStefano V J, Nixon J E. Achilles tendon rupture Pathogenesis, diagnosis and treatment by a modified pullout wire technique. $\mathcal{F}$ Trauma 1972;12:671-7.

70 Grisogono V. Physiotherapy treatment for Achilles tendon injuries. Physiotherapy 1989;75:560-72.

71 Krueger-Franke M, Siebert C H, Scherzer S. Surgical treatment of ruptures of the Achilles tendon: a review of long-term results. Br $\mathcal{F}$ Sports Med 1995;29:121-5.

72 Inglis A E, Scott W N, Sculco T P, Patterson A H. Ruptures of the tendo Achillis. F Bone foint Surg 1976;58-A:990-3.

73 Simmonds F A. The diagnosis of the ruptured Achilles tendon. The Practitioner 1957;1 179:56-8.

74 Scott B W, Alchalabi A. How the Simmonds-Thompson test works. F Bone foint Surg 1992;74-B:314-5.

75 Thompson T C, Doherty J H. Spontaneous rupture of the tendon of Achilles: A new clinical diagnostic test. $\mathcal{F}$ Trauma 1962;2:126-9.

76 Thompson T C. A test for rupture of the tendo Achillis. Acta Orthop Scand 1962;32:461-5.

77 Maffulli N. Clinical tests in sports medicine: more on Achilles tendon. Br F Sports Med 1996;30:250.

78 Matles A L. Rupture of the tendo Achilles: Another diagnostic sign. Bull Hosp foint Dis 1975;36:48-51.

79 O'Brien T. The needle test for complete rupture of the Achilles tendon. F Bone foint Surg 1984;66-A:1099-101.

80 Copeland S. Rupture of the Achilles tendon: a new clinical test. Ann R Coll Surg Engl 1990;72:270-1.

81 Kager H, Zur klinik und diagnostik des Achillessehnenrisses. Chirug 1939;11:691-5.

82 Toygar O. Subkutane ruptur der Achillesschne. (Diagnostik und Behandlungsergebnisse). Helvet Chir Acta 1947;14 209-31.

83 Arner O, Lindholm A, Lindvall $\mathrm{N}$. Roentgen changes in subcutaneous rupture of the Achilles tendon. Acta Chir Scand 1959;116:496-500

84 Maffulli N. Clinical tests in sports medicine. Br $\mathcal{F}$ Sports Med 1996;30:124.

85 Kabbani Y M, Mayer D P. Magnetic resonance imaging of tendon pathology about the foot and ankle. $7 \mathrm{Am}$ Podiat Med Assoc 1993;83:418-20.

86 Deutch A L, Mink J H. Magnetic resonance imaging of musculoskeletal injuries. Radiol Clin North Am 1989;27:983.

87 Crass J R, van de Vegte G L, Harkavy L A. Tendon echogenicity: ex vivo study. Radiology 1988;167:499-501.

88 Fornage B D, Rifkin M D. Ultrasound examination of tendons. Radiol Clin North Am 1988;26:87-107.

89 Barbolini G, Monetti G, Montorsi A, Grandi M. Results with high-definition sonography in the evaluation of Achilles tendon conditions. Italian fournal of Sports Traumatology 1988;10:225-34.

90 Kälebo P, Goksör L-Å, Swärd L, Peterson L. Soft tissue radiography, computed tomography, and ultrasonography of partial Achilles tendon ruptures. Acta Radiol 1990;31 565-70.

91 Campani R, Bottinelli O, Genovese E, et al. Sonography in the evaluation of muscular trauma following exercise. Our experience in the lower limbs. Radiol Med 1990;79:151-62.

92 Maffulli N, Dymond N P, Regine R. Surgical repair of ruptured Achilles tendon in sportsmen and sedentary patients: A longitudinal ultrasound assessment. Int $\mathcal{f}$ Sports Med A longitudinal

93 Fukashiro S, Itoh M, Ichinose Y, Kawakami Y, Fukunaga T Ultrasonography gives directly but noninvasively elastic characteristic of human tendon in vivo. Eur $\mathcal{F}$ Appl Physio 1995;71:555-7.

94 Soma C A, Mandelbaum B R. Repair of acute Achilles tendon ruptures. Orthop Clin N Am 1995;26:239-47.

95 Parsons J R, Rosario A, Weiss A B, Alexander H. Achilles tendon repair with an absorbable polymer-carbon fibre composite. Foot Ankle 1984;5:49-53.

96 Ozaki J, Fujiki J, Sugimoto K, Tamai S, Mashuhara K. Reconstruction of neglected Achilles tendon rupture with Marlex" mesh. Clin Orthop 1989;238:204-8.

97 Hosey G, Kowalchick E, Tesoro D, et al. Comparison of the mechanical and histologic properties of Achilles tendons in New Zealand white rabbits secondarily repaired with Marlex" mesh. F Foot Surg 1991;30:214-33.

98 Kato Y P, Dunn M G, Zawadsky J P, Tria A J, Silver F H. Regeneration of Achilles tendon with a collagen tendon prosthesis: results of a one-yea

99 Lieberman J R, Lozman J, Czajka J, Dougherty J. Repair of Achilles tendon ruptures with Dacron" vascular graft. Clin Orthop 1988;234:204-8.

100 Meyers J F, Grana W A, Lester P. Reconstruction of the anterior cruciate ligament in the dog. Am $\mathcal{f}$ Sports Med 1979;7:85-90.

01 Matthew C A, Moore M J, Campbell L. A quantitative ultrastructural study of collagen fibril formation in the healing extensor digitorum longus tendon of the rat. $\mathcal{F}$ Hand Surg 1987;12-B:313-20. 
102 Gilles $\mathrm{H}$, Chalmers J. The management of fresh ruptures of the tendo Achillis. $\mathcal{F}$ Bone foint Surg 1970;52-A:337-43.

103 Lea R B, Smith L. Non-surgical treatment of tendo Achillis rupture. F Bone foint Surg 1972;54-A:1398-407.

104 Nistor L. Surgical and non-surgical treatment of Achilles tendon rupture: A prospective randomised study. $f$ Bone tendon rupture: A prospecti

105 Stein S R, Luekens C A. Methods and rationale for closed treatment of Achilles tendon ruptures. Am $\mathcal{F}$ Sports Med treatment of

106 Soldatis J J, Goodfellow D B, Wilber J H. End-to-end operative repair of Achilles tendon rupture. Am $\mathcal{f}$ Sports

107 Haertsch P A. The blood supply to the skin of the leg: a post-mortem investigation. Br $\mathcal{F}$ Plastic Surg 1981;34:4707.

108 Aldam C H. Repair of calcaneal tendon ruptures : A safe technique. F Bone foint Surg 1989;71-B:486-8.

109 Carter T R, Fowler P J, Blokker C. Functional postoperative treatment of Achilles tendon repair. Am $\mathcal{F}$ Sports Med 1992;20:459-62.

110 Saw Y, Baltzopoulos V, Lim A, Rostron P K M, Bolton-Magg B G, Calver R F. Early mobilization after operative repair of ruptured Achilles tendon. Injury 1993;24:479-84.

$111 \mathrm{Ma}$ G W C, Griffith T G. Percutaneous repair of acute closed ruptured Achilles tendon: A new technique. Clin closed ruptured Achilles
Orthop 1977;128:247-55.

112 Rowley D I, Scotland T R. Rupture of the Achilles tendon treated by a simple operative procedure. Injury 1982;14: $252-4$.

113 Klein W, Lang D M, Saleh $M$. The use of the Ma-Griffith technique for percutaneous repair of fresh ruptured tendo Achillis. Chir Organi Mov 1991;76:229-36.

114 Hockenbury R T, Johns J C. A biomechanical in vitro comparison of open versus percutaneous repair of tendon Achilles. Foot Ankle 1990;1:67-72.
115 Bradley J P. Tibone J E. Percutaneous and open surgical repairs of Achilles tendon ruptures: A comparative study. Am $\mathcal{F}$ Sports Med 1990;18:188-95.

116 Persson A, Wredmark T. The treatment of total ruptures of the Achilles tendon by plaster immobilisation. Int Orthop 1979;3:149-52.

117 Häggmark T, Eriksson E. Hypotrophy of the soleus muscle in man after Achilles tendon rupture: discussion of the findings obtained by computed tomography and morphologic studies. Am $\mathcal{F}$ Sports Med 1979;7:121-6.

118 Ikai M, Fukunaga T. Calculation of muscle strength per unit cross-sectional area of human muscle by means of ultrasonic measurement. Internationale Zeitschrift fur Angewardte Physiologie Einschliesslich Arbeitsphysiologie 1968;26: 26-32.

119 Vrbova G. Changes in the motor reflexes produced by tenotomy. F Physiol (Lond) 1963; 166:241-50.

120 Häggmark T, Liedberg H, Eriksson E, Wredmark T. Calf muscle atrophy and muscle function after non-operative vs operative treatment of Achilles tendon ruptures. Orthopaedics 1986;9:160-8.

121 Jacobs D, Martens M, van Audekercke R, Mulier J C, Mulier F R. Comparison of conservative and operative treatment of Achilles tendon rupture. Am $\mathcal{f}$ Sports Med 1978;6:107-11.

122 Kellam J F, Hunter G A, McElwain J P. Review of the operative treatment of Achilles tendon rupture. Clin Orthop 1985;201:80-3.

123 Quigley T B, Scheller A D. Surgical repair of the ruptured Achilles tendon: Analysis of 40 patients treated by the same surgeon. Am $₹$ Sports Med 1980;8:244-50.

124 Sejberg D, Hansen L B, Dalsgaard S. Achilles tendon rupture operated on under local anaesthesia: retrospective study of 81 hospitalised patients. Acta Orthop Scand 1990; 61:549-50.
Thirty years ago we dissected frogs for muscle and heart experiments and used kymographs and stethographs. Heart rate and ECG were measured using an old Deveses machine and oxygen uptake was analysed by a Haldane gas analysis apparatus. If you turned the wrong tap you were in trouble. Then we used Douglas bags and Beckman oxygen analysers and in the 1980 s we developed an online system. Because students learn more by doing it themselves were are back to Douglas bags and $\mathrm{O}_{2} / \mathrm{CO}_{2}$ analysers.

Initially anthropometric measurements were limited. Skin folds and somatotype measurements were often taken, but my first attempt to measure body composition in the lab was by volumetric displacement using a wooden tank painted liberally with yacht varnish. I even got the engineers at Brighton Polytechnic to make a helium dilution apparatus, which looked like a coffin and still leaked gases. Now we have a special laboratory and a large plastic tank for underwater weighing that takes over a ton of water without any leaks! When will we get DXA, magnetic resonance imaging or computed tomography?

When I started teaching we had a small fourth year BEd group. Most of the lecturers who taught physiology especially to physical education students, were PE teachers with an interest in physiology and anatomy. There was no sports science. It was remarkable to see the evolution of our discipline throughout my own career during which time I went through four changes of establishment and had to apply for my post three times. No doubt there will be as many changes - and different colleges in the next 30 years-but I shall not experience them. I retired in September.

PETER BALE

Chelsea School of Physical Education, Sports Science, Dance and Leisure Trevin Towers
Gaudick Road Eastbourne BN20 7SP 